\title{
Word and syllable constraints in Indonesian adaptation: OT analysis
}

\author{
Saleh Batais \& Caroline Wiltshire* \\ LSA Annual Meeting, Portland, January 8-11, 2015
}

1. Introduction. In original data consisting of 681 syllabic adaptations of borrowed words produced by 24 native speakers of Indonesian (Batais 2013), we find both deletion and epenthesis to resolve word-final clusters, while word-initial clusters sometimes have epenthesis and sometimes are tolerated intact. Native Indonesian syllables are maximally CVC, and bisyllabic words are the most frequently occurring (Lapoliwa 1981). In this paper, we show that the Indonesian adaptations of Arabic and Dutch loanwords not only obey the obvious Indonesian limit on complex codas, but also reveal the presence of two otherwise subtle constraints: bisyllabic minimal word size (MINWD) and falling sonority across syllable boundaries (SYLLCONT). This analysis furthermore supports the view of borrowing as phonological (Paradis $\&$ LaCharité 1997, 2005) rather than purely phonetic.

2. Background \& methodology. Borrowed words constitute approximately $34 \%$ of the vocabulary of Indonesian (Tadmor 2009), with Dutch (6.4\%) and Arabic (5.7\%) both major contributors. Arabic arrived in the archipelago as early as the $7^{\text {th }}$ century, and Arab traders integrated with Indonesian society, sharing Islam as well as language. Dutch arrived later, with trading relationships in the $16^{\text {th }}$ century and colonial power in the $18^{\text {th }}$ until Independence in 1945. Although the Dutch did not integrate into Indonesian society, their language acquired prestige in the $20^{\text {th }}$ century and provided loans especially in areas of science and technology.

The languages Arabic, Dutch, and Indonesian differ greatly in their phonotactics. Arabic syllables are maximally CVC word-internally, with CVVC and CVCC permitted only wordfinally and in monosyllables (e.g. Al-Ani 1970), while Dutch allows maximal syllables of CCCVCCCC (e.g., Booij 1995). Native Indonesian words have the most limited syllable structure of the three, with a CVC maximum, even word-finally, and while there are a few monosyllabic words in the native Indonesian vocabulary (e.g., di 'in', om 'uncle', and dan 'and'), most words are bisyllabic or larger (Lapoliwa 1981).

Data was gathered from 24 monolingual Indonesian speakers, aged 17-41, balanced in gender, age (teen/adult) and language spoken by parents (Indonesian/regional), none of which affected the results here as all produced the same adaptations. All were born, raised, and living in Jakarta, and all had a maximum of a high school diploma and little or no knowledge of Arabic or Dutch. An Indonesian speaking researcher elicited 111 target loanwords from each speaker, 59 Arabic and 52 Dutch, drawn from Jones (2008) and the first author's collections of observations since 2004. A subset of these words included initial and final consonant clusters, which are examined here. There were 14 distinct target word-final clusters in 15 Arabic words, and 22 distinct target clusters (16 word-initial and 6 word-final) in 36 Dutch words.

3. Results. Monosyllabic Arabic inputs with final consonant clusters are always adapted through vowel insertion, resulting in bisyllabic words in Indonesian as shown in Table 1. The location of epenthesis depends on the nature of the final consonant cluster; if sonority rises across the cluster, (1a), a copy vowel is inserted between the two final consonants ( $71 \%$ of the cases), while

\footnotetext{
${ }^{*}$ We thank the audience at the LSA Annual Meeting in Portland, especially Bruce Hayes, for useful comments, and regret that this abstract is faithful to our presentation rather than incorporating their insights. Authors: Salah Batais King Saud University (salehbatais@hotmail.com) \& Caroline Wiltshire, University of Florida (wiltshir@ufl.edu).
} 
if the cluster is flat or falling in sonority $(1 \mathrm{~b}), \mathrm{a} / \mathrm{u} /$ is epenthesized after the consonant cluster (29\% of the cases).

\begin{tabular}{llll} 
Adaptation & Arabic & Indonesian & Gloss \\
\hline (a) medial & $/$ fikr/ & [pikir] & 'to think' \\
epenthesis & $/$ fahm/ & [paham] & 'to understand' \\
& $/$ /umr/ & [Pumur] & 'age' \\
\hline (b) final & $/$ waqt/ & {$[$ waktu] } & 'time' \\
epenthesis & $/$ Aaldz/ & [saldzu & 'snow' \\
\hline
\end{tabular}

Table 1: Adaptations of Arabic loanwords with epenthesis

Dutch monosyllabic inputs with initial CC clusters also take medial epenthesis (2a), but polysyllabic inputs allow initial clusters to surface intact (2b). If a polysyllabic input has a final cluster, the final consonant is deleted $(2 \mathrm{c})$.

\begin{tabular}{llll} 
Adaptation & Dutch & Indonesian & Gloss \\
\hline $\begin{array}{l}\text { (a) medial } \\
\text { epenthesis }\end{array}$ & /straf/ & [sotrap] & 'punishment' \\
'blus/ & [bolus] & 'scandal' \\
\hline (b) no change & $/$ sxandal/ & [skandal] & 'protest' \\
\hline (c) final deletion & $/$ protest/ & [protes] & 'bandage' \\
& /vorband / & [porban] & 'ban' \\
\hline
\end{tabular}

Table 2: Adaptations of Dutch loanwords with epenthesis, no change, and deletion

The generalizations from the results are as follows. Epenthetic vowels appear in monosyllables, resolving both word-final and word-initial clusters. In polysyllables, final consonants are lost from word-final clusters, while initial consonant clusters in polysyllables are tolerated.

4. Analysis. We formulate our analysis in Optimality Theory, in order to demonstrate the relative importance of phonotactic factors in Indonesian. We see from the results that epenthesis resolves consonant clusters. However, while constraints against complex onsets and complex codas are generally obeyed in Indonesian, they do not trigger epenthesis on their own, as seen in the polysyllabic borrowings from Dutch. Epenthesis is seen in monosyllables only, suggesting the importance of a constraint MINWD ("a lexical word must be bisyllabic minimally", Yip 1993), which must outrank the faithfulness constraint DEP-IO(V). While coda clusters in monosyllables benefit from epenthesis, final clusters in polysyllables are simplified, revealing the ranking *COMPCODA $>>$ MAX-IO $(\mathrm{C})$. Conversely, the tolerance of onset clusters in polsyllables requires the opposite relative ranking MAX-IO $(\mathrm{C})>>$ *COMPONSET.

The location of epenthesis for final clusters reveals the importance of a constraint against consonant clusters rising in sonority across a syllable boundary, or SYLCONT (Murray and Vennemann 1983). This constraint requires that when epenthetic vowels appear, they do so within a cluster of consonants, despite breaking up a sequence of segments that is contiguous in the input, hence violating CONTIG-IO (Kager 1999). Therefore, SYLCONT outranks ConTIG-IO, although the location of this ranking amongst the other constraints is not fully determinable. The ranking arguments are summarized as follows: 
- Epenthesis to make monosyllables into bisyllables: MiNWd $>$ DeP-IO(V)

- Epenthesis in onset clusters in monosyllables: MinWD $>>$ DEP-IO(V), *COMPONSET

- Deletion word-finally in polysyllables: MinWD,DeP-IO(V), ${ }^{*}$ CompCodA $>>$ MAX-IO(C)

- Tolerate onset clusters in polysyllables: MinWD, DEP-IO(V) >> MAX-IO(C) >> *COMPONSET

- Epenthesis inside clusters with rising sonority but after clusters with falling sonority: SYLCONT $>>$ CONTIG-IO

Combining these partial rankings into a single ranking, as in Tables (3) \& (4) below, we see that in monosyllables, epenthesis results from the high ranking of MINWD. The mini ranking of SYLCONT above CONTIG could be placed anywhere in the tableau and still correctly break the time in favor of the winning [zikir] over the losing *[zikri]. This result of epenthesis breaking consonant clusters holds true for both Arabic monosyllables with final clusters and Dutch monosyllables with initial clusters, since MINWD rules out both faithful candidates and any candidates with deletion.

\begin{tabular}{|r|c|c|c:c:c|c|c|}
\hline \multicolumn{1}{|l}{$/$ ðikr/ } & MINWD & SYLCONT & CONTIG & DEPV & $\begin{array}{c}* \text { COMP } \\
\text { CODA }\end{array}$ & MAXC & $\begin{array}{c}* \text { COMP } \\
\text { ONS }\end{array}$ \\
\hline$[$ zikr] & $* !$ & & & & $*$ & & \\
\hline$[$ zikir] & & & $*$ & $*$ & & & \\
\hline$[$ zikri] & & $* !$ & & $*$ & & & \\
\hline$[\mathrm{zik}]$ & $* !$ & & & & & $*$ & \\
\hline
\end{tabular}

Table 3: Analysis of Arabic monosyllable borrowed into Indonesian

However, when an input can satisfy MINWD despite deletion, as in polysyllabic Dutch inputs, a MAX-(C) violation that satisfied *COMPCODA provides the preferred output. The example in Table 4 also illustrates that the low ranking of *COMPONSET results in onset clusters in polysyllables remaining intact.

\begin{tabular}{|r|c|l|c|c|c|c|c|}
\hline /protest/ & MINWD & SYLCONT & CONTIG & DEPV & $\begin{array}{c}* \text { COMP } \\
\text { CODA }\end{array}$ & MAXC & $\begin{array}{c}* \text { COMP } \\
\text { ONS }\end{array}$ \\
\hline$[$ protest] & & & & & $* !$ & & $*$ \\
\hline$[$ protes] & & & & & & $*$ & $*$ \\
\hline$[$ porotes] & & & $* !$ & $* !$ & & $*$ & \\
\hline$[$ potes] & & & & & & $* * !$ & \\
\hline
\end{tabular}

Table 4: Analysis of Dutch polysyllable borrowed into Indonesian

As illustrated above, the markedness constraints MinWD, *COMPLEXCODA, and SYLLCONT dominate faithfulness constraints in Indonesian to ensure coda cluster simplification through either vowel epenthesis in monosyllabic inputs or consonant truncation in multisyllabic inputs. The first two of these constraints, MINWD and *COMPLEXCODA, are widely obeyed in native Indonesian phonology phonology (e.g. kapan 'when', buruh 'labor', sisik 'scale', bumbu 'spices', rindu 'longing'). The SYLLCONT constraint which determines the difference in epenthesis sites (medial vs. edge) seen in Table 1 (a)-(b) appears to express itself only in the borrowed words which require epenthesis. The quality of the vowel inserted also differs in Table 
1, which could be analyzed in terms of the interactions of an identity constraint S-IDENT-IO (F) (adjacent syllables are identical in their specification of vowel features, Krämer 2003) with a markedness constraint, although we omit this analysis for lack of space.

5. Conclusions. By showing that several distinct adaptations are conditioned by the same markedness constraints, the OT analysis corroborates the view that the Indonesian syllabic adaptation is a phonological process, not a purely phonetic operation relying solely on acoustic saliency or perception (Silverman 1992; Yip 1993 \& 2006; Peperkamp \& Dupoux 2003; Peperkamp 2005). In particular, the different treatment of final consonant clusters, with epenthesis in monosyllables vs. deletion in polysyllables, is based not on the perceptibility of such clusters, but rather determined by a phonological constraint on word-size. If the Indonesian syllabic adaptations were determined by perception alone, word-final obstruents in Arabic /waqt/ 'time', /sabt/ 'Saturday', and Dutch /lamp/ 'lamp' and /protest/ 'protest' should be deleted owing to their weak cues in final clusters. Instead, such cluster-final obstruents are phonologically preserved by post-C2 vowel epenthesis exactly when the words would otherwise be monosyllabic, revealing the preference in Indonesian phonology for minimally bisyllabic words, and yielding [waktu], [sabtu], [lampu] and [protes]. While perceptibility factors certainly can play a role in adaptations, these factors are not alone in determining the borrowed forms of Dutch and Arabic loans in Indonesian.

\section{References}

Al-Ani, Salman. 1970.. Arabic phonology: An acoustical and physiological investigation. The Hague: Mouton.

Batais, Saleh. 2013. Consonantal and syllabic repairs of Arabic and Dutch loanwords in Indonesian: A phonological account. Gainesville, FL: Univ. of Florida dissertation.

Booij, Geert. 1995. The phonology of Dutch. Oxford: Clarendon Press.

Jones, Russell. 2008. Loan-words in Indonesian and Malay. Jakarta, Indonesia: Yayasan Obor Indonesia.

Kager, Rene. 1999. Optimality Theory. Cambridge: Cambridge University Press.

Krämer, Martin. 2003. Vowel harmony and correspondence theory. New York: Mouton de Gruyter.

Lapoliwa, Hans. 1981. A generative approach to the phonology of Bahasa Indonesia. Australia: Australian National University.

Murray, Robert and Theo Vennemann. 1983. Sound change and syllable structure in Germanic phonology. Language 59. 514-528.

Paradis, Carole, and Darlene LaCharité . 1997. Preservation and minimality in loanword adaptation. Journal of Linguistics 33. 379-430.

Paradis, Carole, and Darlene LaCharité. 2005. Category preservation and proximity versus phonetic approximation in loanword adaptation. Linguistic Inquiry 36. 223-258.

Peperkamp, Sharon. 2005. A psycholinguistic theory of loanword adaptations. Berkeley Linguistic Society (BLS) 30. 341-352.

Peperkamp, Sharon, and Emmanuel Dupoux. 2003. Reinterpreting loanword adaptations: The role of perception. Proceedings of the 15th International Congress of Phonetic Sciences, 367-370. http://www.lscp.net/persons/ dupoux/papers/Peperkamp_Dupoux_2003_Reinterpreting_loanword_adaptations_perception.In_ICPS15.pdf

Silverman, Daniel. 1992. Multiple scansions in loanword phonology: Evidence from Cantonese. Phonology 9. 289328.

Tadmor, Uri. 2009. Loanwords in Indonesian. In Martin Haspelmath \& Uri Tadmor (eds.), Loanwords in the world's languages: A comparative handbook. 686-716. Berlin: Mouton de Gruyter.

Yip, Moira. 1993. Cantonese loanword phonology and optimality theory. Journal of East Asian Linguistics 2. 261291.

Yip, Moira. 2006. The symbiosis between perception and grammar in loanword phonology. Lingua 116. 950-975. 